Portland State University

PDXScholar

Winter 2020

\title{
Economic Analysis of Green Marketing: The \\ Correlation Between Consumers and Firms Through Environmental Incentives
}

Naomi Joyce

Portland State University

Follow this and additional works at: https://pdxscholar.library.pdx.edu/honorstheses

Part of the Behavioral Economics Commons

Let us know how access to this document benefits you.

\section{Recommended Citation}

Joyce, Naomi, "Economic Analysis of Green Marketing: The Correlation Between Consumers and Firms Through Environmental Incentives" (2020). University Honors Theses. Paper 946.

https://doi.org/10.15760/honors.969

This Thesis is brought to you for free and open access. It has been accepted for inclusion in University Honors Theses by an authorized administrator of PDXScholar. Please contact us if we can make this document more accessible: pdxscholar@pdx.edu. 
Economic Analysis of Green Marketing: The Correlation Between

Consumers and Firms Through Environmental Incentives

\author{
by \\ Naomi Joyce \\ An undergraduate honors thesis submitted in partial fulfillment of the \\ requirements for the degree of \\ Bachelor of Science \\ in \\ University Honors \\ and \\ Economics \\ Thesis Advisor \\ Dr. Sahan Dissanayake
}

Portland State University

2020 


\begin{abstract}
This thesis will seek to explore and analyze incentives in the market with relation to consumers and firms interacting in the current economic and environmental situation of the United States. These incentives are crucial to understanding the relationship between green consumerism and firm positions in the market. By analyzing the characteristics of green consumers and their reactions of firms, a better understanding of the economic relationship of firms and consumers for the future will become more apparent. The green consumer exhibits personal patterns in their purchasing habits which firms can utilize to attract the green consumer while increasing profits. When the incentives used by firms to drive green consumers are analyzed in relation to the consumer perspective, firms are able to economically exploit them to increase the impacts of green marketing and work towards environmental preservation and sustainability.
\end{abstract}

Key Words: Economic Analysis, Green Marketing, Consumer Behavior, Carbon Analysis, Incentives, Sustainability.

\title{
1.0 Introduction
}

It is no secret that greenhouse gas emissions around the globe have been increasing at alarming rates and are continuing to climb at an exponential rate. In Figure 1 the National Oceanic and Atmospheric Administration (NOAA) shows carbon emissions since 1750 that have increased exponentially within the last several decades. 


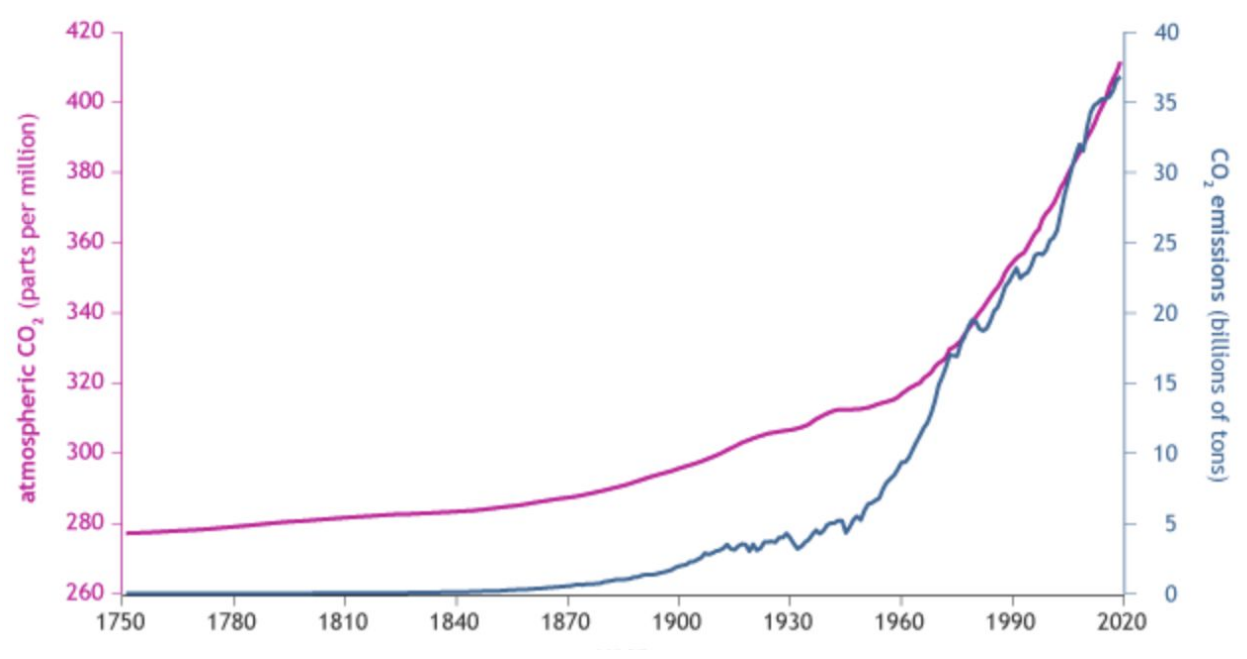

Figure 1: NOAA carbon emissions progression

The increase of greenhouse gas emissions by firms and individuals has negatively impacted both the environment as well as our communities and some people are starting to take action to offset these negative effects (Hertwich, 2009).

With a goal of net zero emissions, individuals are taking action and it is impacting the firms they interact with. As knowledge of global and domestic environmental issues arises from increased greenhouse gases, more individuals are working to reduce their carbon footprint, and firms are taking notice (Pandey, 2011). Thus these people have become the green consumer creating an ever growing segment of green marketing (Do, 2009).

So what are the characteristics of green consumers that firms can use to incentivize them in order to increase the success of green marketing and increase environmental sustainability? To answer that, the basics of understanding the green consumer and green marketing must first be addressed. Green marketing can be defined as "the effort by a company to design, promote, price and distribute products in a manner which promotes environmental protection" (Suki p. 263 2016). Green consumers are those whose purchasing patterns indicate an elevated concern for 
environmental sustainability and consumers whose beliefs are greatly influenced by the concern for environmental sustainability.

The green consumer segment has been changing the distribution of spending in firms due to their environmental beliefs therefore firms are responding by changing products and procedures in order to maintain relationships with these consumers. As the demand for green and sustainable products increases, firms work to please these consumers (Grant, 2008). With greater awareness of the environmental impacts firms have, the segment of consumers invested in sustainability increases and a moral discussion of company sustainability emerges to get ahead of simply producing only what is demanded of the green consumer (Suk, 2016). Some company cultures are shifting from simply being profit based with every action based on the bottom line as their environmental impacts are exposed and examined (Woolverton, 2010).

This thesis will seek to examine the motivations behind green consumers' purchasing decisions and behaviors as well as marketing to green consumers and building a green company on the firm side. In order to accomplish this, a preliminary look at the global carbon footprint that has been a key component of the boom of green consumers who feel a social and personal responsibility to environmental sustainability.

\subsection{Global Carbon Footprint}

Analyzing the carbon footprint is a key measure for determining environmental effects that impact communities and ecosystems. Within the Earth's atmosphere the levels of greenhouse gas emissions have always fluctuated throughout history; while these fluctuations are naturally occurring, the largest concern for $\mathrm{CO} 2$ and greenhouse gases today is the rate at which these levels are rising due to human activity. These greenhouse gases have been beneficial to 
human life in their assistance in production of goods and services through eight classifications: "construction, shelter, food, clothing, mobility, manufactured products, services, and trade" (Hertwich, p.6414, 2009). Globally breaking down the usage of Greenhouse gas emissions; $72 \%$ are used in household consumption, the government consumes $10 \%$, while 18 percent goes to investments. To break this down further accounting for GHG emissions, food is at $20 \%$, maintenance and operation of residence is $19 \%$ and transportation is at $17 \%$. These global averages vary depending on countries: developing countries emit a greater percentage of GHG for services and food while more developed countries emit more GHG for transportation, mobility, and manufactured goods; for rich and dominant countries these numbers of GHG continue to rise at increasing rates (Hertwich, p.6414, 2009)

Through examination of ice cores as well as other tools, scientists have been able to map the patterns of $\mathrm{CO} 2$ levels in our earth's atmosphere with particular accuracy over the last thousands years.

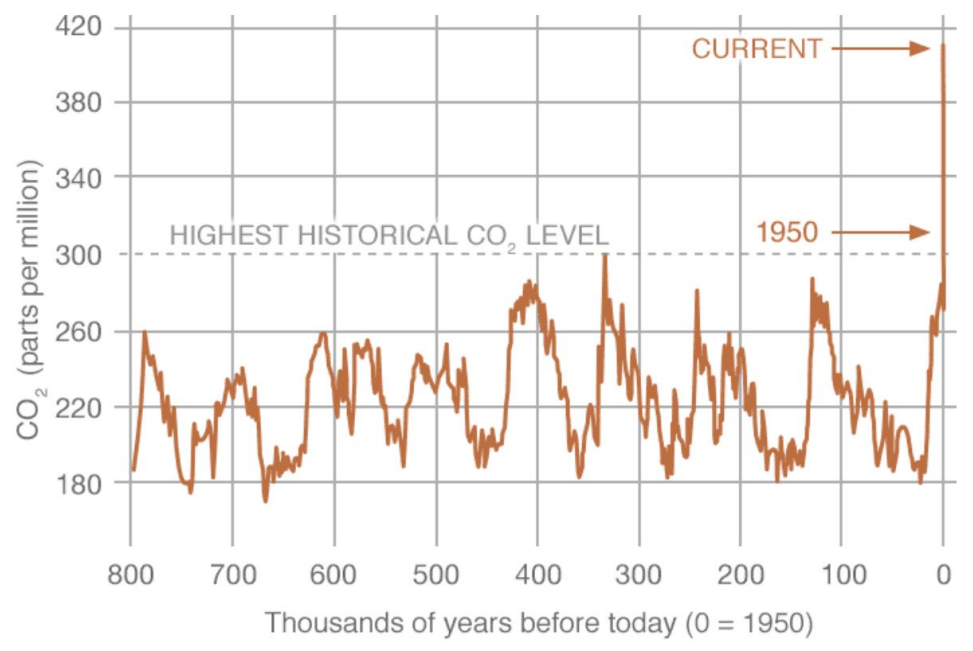

Figure 2: Proxy Measurements of $\mathrm{CO} 2$ in the Earth's atmosphere in ppm

Figure 2 shows the average CO2 levels in the Earth's atmosphere from 800,000 years ago to today's present levels of $\mathrm{CO} 2$ emissions. Prior to the present day, the highest recorded level of 
$\mathrm{CO} 2$ in the atmosphere was over 300 million years ago with fluctuations occurring over the millennia. In 1950 the CO2 levels grew above this historic level of 300ppm and has increased exponentially to almost 400ppm today (NASA). This rapid growth of carbon emissions is a great concern that is quickly becoming a global issue with great precedence. By taking a closer look at the most recent decade of increased emissions, we are able to identify significant changes. Figure 2 below captures a visual representation of this exponential growth of $\mathrm{CO} 2$ emissions across the globe. Using Atmospheric Infrared Sounder (AIRS) NASA shows the Mid-Tropospheric levels of CO2 from September of 2002 to September of 2016.

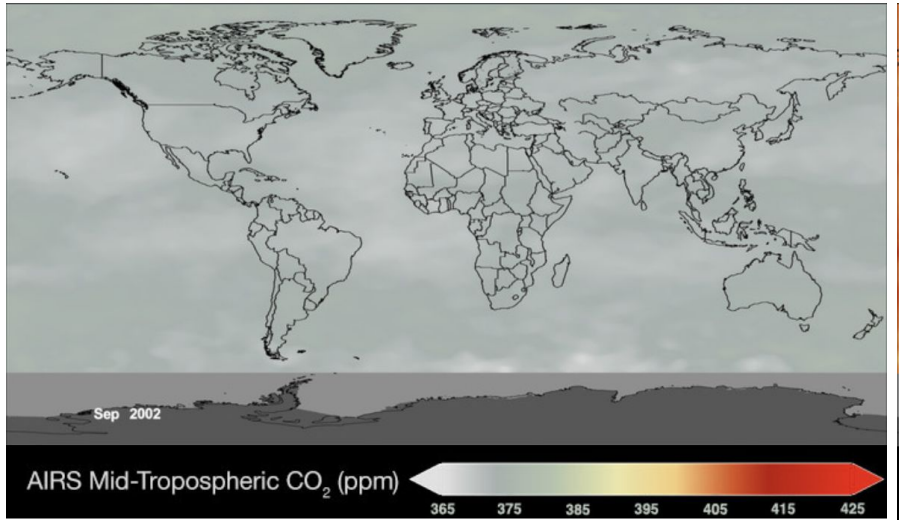

(A)

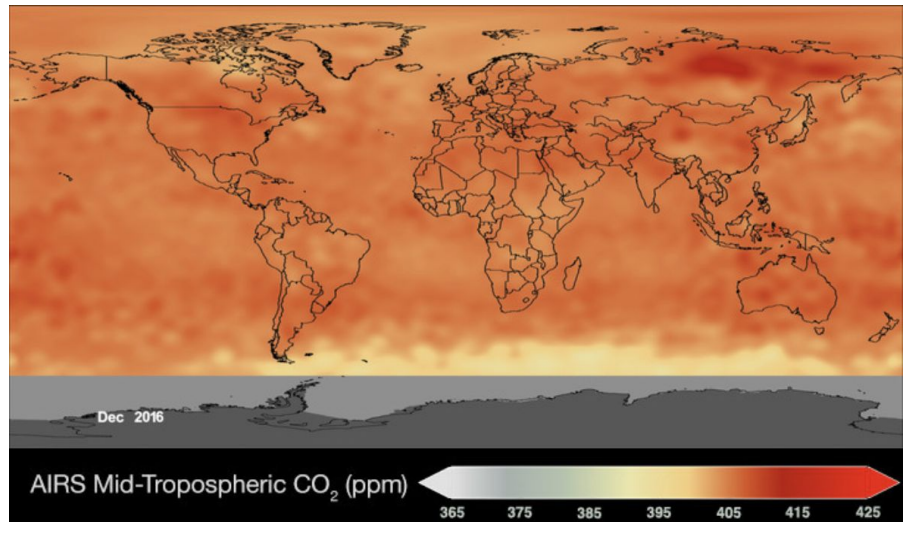

(B)

Figure 3: Global Atmospheric Infrared Sounder Data of Mid-Tropospheric CO2 Levels in ppm (A) September 2002, (B) December 2016

Figure 3(A) shows a global average of global $\mathrm{CO} 2$ averages around $375 \mathrm{CO} 2 \mathrm{ppm}-$ which as we have seen is already far above the previous historic average-in the Mid-Tropospheric level of the atmosphere; as time progresses, in December of 2016 the average CO2ppm in the mid-tropospheric atmosphere ranges from 400-415 globally. This dramatic increase in a short period of time shows a pattern of continued and exponential growth of $\mathrm{CO} 2$ emissions in the earth's atmosphere. 
Now that the overall increase of Carbon emissions globally has been established it is important to look into the breakdown regionally to determine the source and location of greatest greenhouse gas emissions. Figure 3 shows the global distribution of $\mathrm{CO} 2$ emissions for each country from September of 2020.

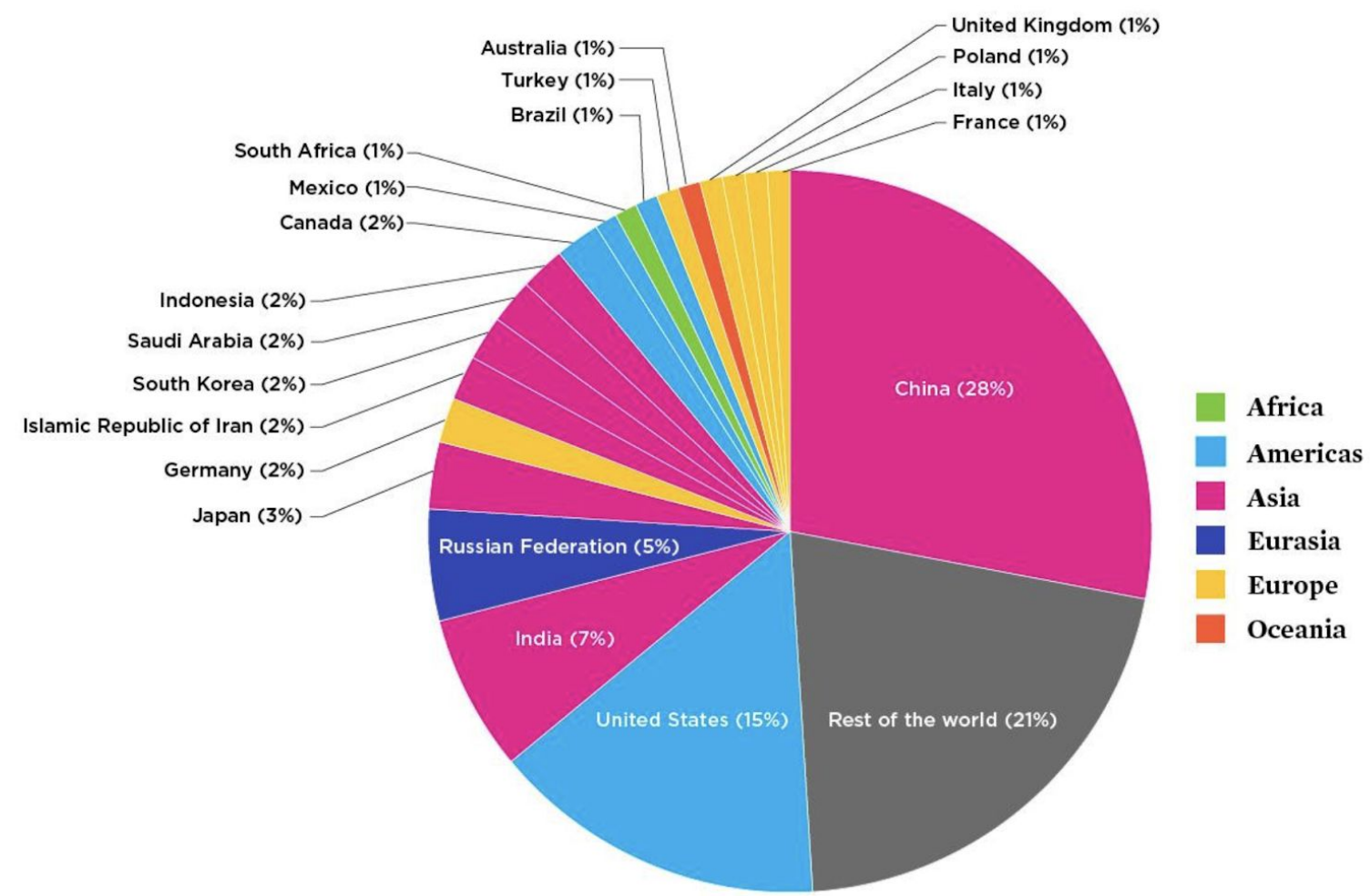

Figure 4: Share of CO2 Emission by Country: taken from 2020 Union of Concerned Scientists. (Data: earth systems science data 1783-1838, 2019)

As shown by figure 4, the largest emissions of GHG by country belong to China with the United States following with a large portion of the emissions; regionally it is clear that Asia produces the most significant portion emissions with a total of $46 \%$ of global emissions coming from the region (UCSUSA). The table below shows the countries in the world with the highest levels of $\mathrm{CO} 2$ emissions. 
A

\begin{tabular}{l|l|r}
\hline Rank & Country & CO2 emissions (total) \\
\hline 1 & China & 10.06GT \\
\hline 2 & United States & 5.41GT \\
\hline 3 & India & $2.65 \mathrm{GT}$ \\
\hline 4 & Russian Federation & $1.71 \mathrm{GT}$ \\
\hline 5 & Japan & $1.16 \mathrm{GT}$ \\
\hline 6 & Germany & $0.75 \mathrm{GT}$ \\
\hline 7 & Islamic Republic of Iran & $0.72 \mathrm{GT}$ \\
\hline 8 & South Korea & $0.65 \mathrm{GT}$ \\
\hline 9 & Saudi Arabia & $0.62 \mathrm{GT}$ \\
\hline 10 & Indonesia & $0.61 \mathrm{GT}$
\end{tabular}

B

\begin{tabular}{l|l|r|}
\hline Rank & Country & $\mathbf{C O}_{2}$ emissions (total) \\
\hline 1 & Saudi Arabia & $18.48 \mathrm{~T}$ \\
\hline 2 & Kazakhstan & $17.60 \mathrm{~T}$ \\
\hline 3 & Australia & $16.92 \mathrm{~T}$ \\
\hline 4 & United States & $16.56 \mathrm{~T}$ \\
\hline 5 & Canada & $15.32 \mathrm{~T}$ \\
\hline 6 & South Korea & $12.89 \mathrm{~T}$ \\
\hline 7 & Russian Federation & $11.74 \mathrm{~T}$ \\
\hline 8 & Japan & $9.13 \mathrm{~T}$ \\
\hline 9 & Germany & $9.12 \mathrm{~T}$ \\
\hline 10 & Poland & $9.08 \mathrm{~T}$ \\
\hline
\end{tabular}

Table 1: CO2 emissions by the top 10 countries 2018 (UCSUSA)

(A) Countries that emitted the most CO2 (B) Ranking of CO2 Emissions Per Capita(UCSUSA)

The distinction between Table 1(A) and Table 1(B) shows a substantial difference between total carbon emissions and emissions per capita. The significance of these differences can be shown linearly in graph 1 . As expenditure increases, $\mathrm{CO} 2$ emissions per capita rise. China leads with 
total emissions in Table 1(A) but does not appear as a nation with the highest emissions per capita.

As shown, the emissions globally have had an influence on environmental factors that influence the environment as well as communities. Taking this data into consideration for how business is conducted and the purchases of consumers and their buying habits can show a trend for the green consumer market. By targeting green consumers who are concerned with and aware of the greenhouse gas emissions, firms are able to contribute to emission reductions and make an impact on sustainability; in order to do this the green consumer must first be examined closely.

\subsection{The Green Consumer}

The green consumer is central to the discussion of green marketing because they are the largest drivers of the market. The demand of all consumers directly correlates with the supply produced by firms; with the increase in the number of green consumers, their characteristics, purchase habits, and ideals become crucial to the market of green goods and essential for firms to understand in an effort to profit from the green consumer.

\subsection{Consumer Profile}

Do Paco states that consumers today have become increasingly interested in making purchases that reflect environmentally sustainable choices. In order to create a consumer profile researchers must analyze consumer preferences and purchasing behavior. Identifying a target market and creating consumer profiles allows firms to market towards these particular consumers in an effective manner (Do Paco p.18, 2009). 
Often, these green consumers belong to more than one customer segment because of their interest in buying green, but there are barriers that prevent people from reacting to their green preferences when faced with making a purchase. Here are five major barriers that green consumers are presented with in their effort their buy green: (1) a simple lack of awareness; most consumers are aware of global environmental concerns and have an interest in buying sustainable products but are overwhelmed with where to begin looking while their good intentions are overshadowed by misrepresented 'green' products. (2) There is sometimes a negative perception surrounding green products, some consumers believe that the green choice is an alternative to the best option and that purchasing green over it's non-green equivalent is a compromise in quality. (3) Consumers have a tendency to question or distrust green products; scientists and their environmental claims are trusted by green consumers but their trust waivers with businesses and government in fear of being misled in their purchases. (4) The higher prices of green products prove to be problematic for some demographics of green consumers, while their intentions and motives of purchasing green are well established, the monetary commitment can prove problematic. (5) Finally, the lack of availability of green products means that even consumers who want to buy environmentally sustainable products and have the means to do so are unable to find the products because businesses are not stocking these products (Bonini p.58-59, 2008).

In order to create accurate segmentation for green consumers, the components of their characteristics and behavior must be examined for marketing products properly for segmentation: demographics, psychographics, and behavioral criteria are essential (Finisterra 2010). For demographic criteria, differences emerge based on age, gender, level of education, income and geographic region when identifying green consumers. Studies show that gender has a 
lower influence for green consumers whereas income level is a large contributing factor and increased income "generally correlates positively with environmental sensitivity" (Finisterra 2010). Because income is a key determinant for the green consumer profile, age of the consumer segment is altered to match income levels in addition to age relating to the behavioral characteristics of consumers (Finisterra 2010). The psychographic criteria used to determine a consumer profile in segmentation is based on ideas of lifestyle: two factors within this section which researchers focus on are locus of control and alienation. The locus of control allows a consumer to perceive the reward received due to a particular behavior or action and alienation allows for cognitive perception of being isolated for one's culture, society or community. Psychographically, with a focus on locus of control and alienation, research shows that personality variables correlate with environmental conscientiousness (Finisterra p.20, 2010). The behavioral criteria analyzes and uses consumer relation to products in the market using factors such as "knowledge, attitude, use of a product or response to a product, with an attempt also being made to understand their buying behaviour from the viewpoint of users and non-users" (Finisterra p.20, 2010).

The demographic, psychographic, and behavioural criteria used to distinguish different consumers and profiles of green consumers creates an intricate web of personalized profiles that work together to create the entire green consumer group. Do Paco created a simple strategic model for the buying behavior of the green consumer shown in Figure 4. 


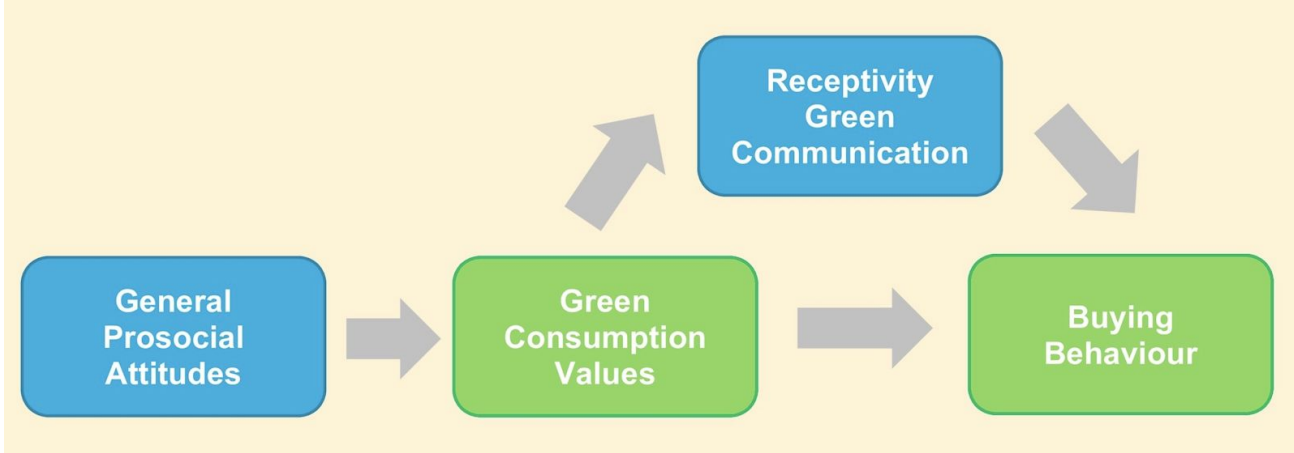

Figure 5: Consumer behavior model for green consumption (Do Paco p.998, 2019)

Figure 5 shows the route of general attitudes of consumers moving towards those with their green consumption values as a priority resulting in their buying behavior.

In the article Green consumer market segmentation: empirical findings from Portugal, Finisterra ultimately profiles the segments of green consumers. This is done by looking into the correlation between consumers and ten factors: Environmentally friendly buying behavior, environmental activism, environmental knowledge, environmental concern, recycling, perceived consumer effects, resource saving, economic factor, and skepticism towards environmental claims (2010). The results from the study produced three major segments shown in Table 2.

\begin{tabular}{|c|c|c|}
\hline Segment 1 & Segment 2 & Segment 3 \\
\hline $\begin{array}{c}\text { Uncommitted } \\
36 \%\end{array}$ & $\begin{array}{c}\text { Green Activists } \\
35 \%\end{array}$ & $\begin{array}{c}\text { Undefined } \\
29 \%\end{array}$ \\
\hline $\begin{array}{ll}\text { - } & \text { Younger (18-34) } \\
\text { - } & \text { High education level } \\
\text { - } & \text { Urban } \\
\text { - } & \text { Lower income } \\
\text { - } & \text { Lower willingness to } \\
\text { pay } \\
\text { - Claim to have } \\
\text { knowledge on } \\
\text { environmental issues }\end{array}$ & $\begin{array}{l}\text { - Age: } 25-34 \text { \& } 45-54 \\
\text { - Highest education levels } \\
\text { - High income } \\
\text { - Upper level positions in } \\
\text { careers } \\
\text { - Favor environmental } \\
\text { aspects } \\
\text { - Skeptical of environmental } \\
\text { ads }\end{array}$ & $\begin{array}{ll}\text { - } & \text { Older age } \\
\text { - } & \text { Lower education levels } \\
\text { - } & \text { Skeptical of } \\
\text { advertisements } \\
\text { - } & \text { Little knowledge on } \\
\text { environmental issues } \\
\text { - Little thought or care for } \\
\text { environmental issues }\end{array}$ \\
\hline
\end{tabular}

Table 2: Segments of Green Consumers (developed from Finisterra's research) 
From table 2, it is shown that the consumer segment with the greatest interest in purchasing within the green market is segment two-the green activist. With high levels of education, this group has superior knowledge of environmental issues and their high level of income allows the consumers in the segment to act on their desires to to purchase products that are environmentally sustainable even if that requires spending a higher amount. One way that segment two is attempting to make an impact on environmental issues is a diversion away from the once monumentally popular fast fashion.

\section{Case Study:}

\section{The Fall of Fast Fashion in The Eyes of Green Consumers}

While fast fashion is still incredibly popular in today's economy with social narratives, the active green consumer is making an effort to shop elsewhere. There are several reasons why fast fashion has become such a lucrative business: the industry offers low cost, high speed, trendy clothing right away (Joy 2012). Fast fashion is, according to Vertica Bhardwaj and Ann Fairhurst, "low-cost clothing collections based on current, high-cost luxury fashion trends - is, by its very nature, a fast-response system that encourages disposability" (2010). For those in the industry, the market is highly competitive; constant changes to stock, cheap prices, and new clothes regularly bring consumers back to purchase more on a more frequent basis (Bhardwaj, 2010). Popular stores such as Forever 21, H\&M, and Zara produce these cheap products that encourage consumers to buy more for the lower price and frequent the stores to see what is new. 
Of the downfalls of fast fashion, the amount of waste produced is a great concern for those conscientious with environmental impact. The lack of sustainability offered by the fast fashion brands are driving consumers away to find more ethically sourced and environmentally friendly products. Research has found that much of the fast fashion purchases are made by younger consumers and while they are concerned about the environment and the social impact their purchasing decisions have, they are unlikely to apply these principles to fashion consumption (Joy, p.280 2012). The fast fashion industry also provides a level of convenience with a low level of commitment to the products which make them attractive to many consumers.

For those consumers who are not drawn into the allure of fast fashion and the consumers who are trying to break away from the fast fashion industry in order to shop more sustainably, there are several options. While the options to steer away from fast fashion are more expensive, the ideals and characteristics of the green consumer take precedence over the price and convenience. Consumers such as those in segment two of the market above, the 'green activist' segment would be an ideal target for ethically and sustainably sourced fashion products. Buying from local stores as well as from companies with a mission for sustainability allows green consumers to feel better about their purchases, and luxury brands that are built to last are a viable alternative (Joy 2012). With luxury brands it should be noted that they are a good choice when consumers are buying them for their sustainability, consumers with high amounts of disposable income who purchase 
these items simply as a status symbol to be worn briefly before replacing them

with the newest luxury trend are not green consumers.

By purchasing sustainable products that produce less waste green

consumers are steering away from the fast fashion industry in order to act on environmental actions.

\subsection{Firms and Green Marketing}

The firm side of the green market is responsible for the products produced and supplied; the products supplied are impacted by the green consumer and their demand for particular products. When the demand for a new or different product becomes apparent in the market, firms will shift what they supply and compete with one another to meet these demands; this also allows for new businesses to be introduced into the market in order to meet the demand of consumers.

Firms must be consistent on which consumers they intend to attract; figure 6 shows the cues of consumers looking to make a purchase.

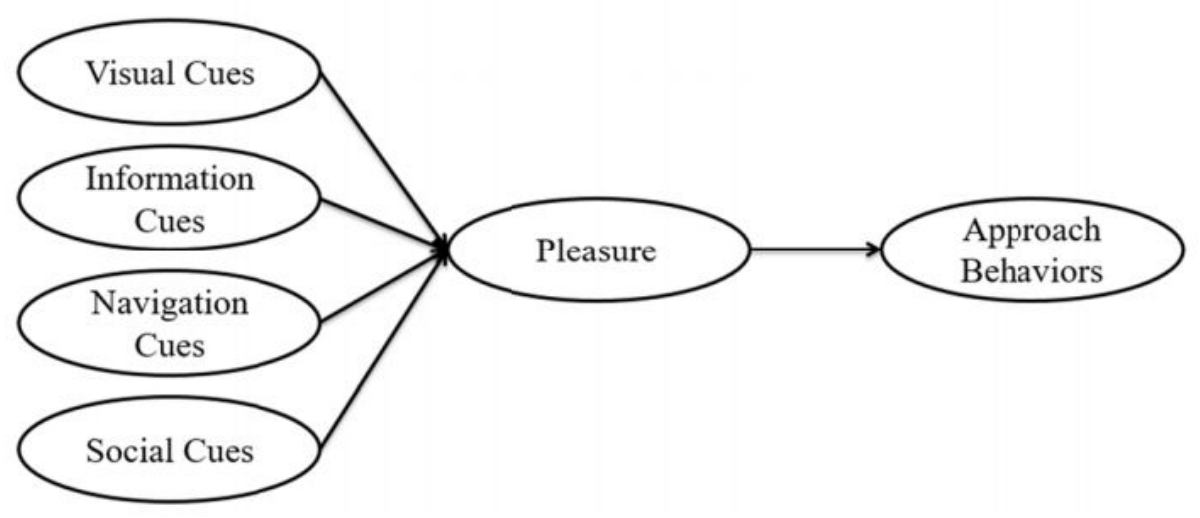

Figure 6: Cues which generate positive emotion which leads to a consumer's approach behavior (Koo p.40 2017) 
These consumer cues vary depending on the beliefs of consumers and their objectives. For green consumers, environmental concern, recycling, perceived consumer effects, packaging, and energy are all factors that would contribute to pleasure leading to their approach behavior (Finisterra 2010).

In order to get a better understanding of the firm's role in green marketing, brand development and corporate culture are analyzed with a look at Amazon.com's approach as one of the largest companies in the world. It should be noted that there are several ways to improve sustainability, "Businesses alone cannot lead consumers from intention to action. In many instances, the government and the civil sector need to be heavily involved to achieve long-lasting changes in consumer behavior" (Bonini 2008). While there are different approaches to increased environmental sustainability on the firm side, this analysis focuses only on the private sector and firms individually through their own decisions for marketing and business development.

\subsection{Green Brand Development}

The majority of green brands are successful because they either provide an alternative technology or they are a company that runs on green principles (Grant p. 25 2008).

While there will always be supply and demand between consumers and firms to drive the growth of green marketing, the social responsibility of firms also plays an important role. Consumers who are already knowledgeable about environmental concerns seek out companies that sell to their interests while avoiding companies that lack sustainable products. There are other consumers who are less knowledgeable on environmentally sustainable products, for these consumers, if a company were to promote or have a section devoted to sustainable products, this 
may spark an interest for consumers who are emerging into the green consumer category (Suki p.266 2016).

While creating a 'green brand' can benefit a firm to draw in the green consumer, caution and regulation are necessary. A popular trend that emerges in research of green consumers is a skepticism regarding the authenticity and factuality of environmental claims from businesses (Finisterra 2010). Lack of consistency among claims of a product sourcing and level of environmental sustainability throughout brands means consumers become suspicious of their purchases. While promoting sustainable green products can benefit and bring profit to a firm, overextending the factuality of the product can harm the firm. If a product is labeled 'green' and it is later proven to not be as sustainable as the firm initially claimed, consumers feel cheated and look to purchase elsewhere; the insincerity of a brand and failure to be forthcoming with consumers tarnishes their reputation which is a difficult issue for a brand to come back from. There are some discrepancies about when a product is marked as 'green;" at the individual level, firms produce statements of socially responsible behavior for themselves but quite often the firm's statement and intent is not the only factor in the mark of a green product. Product labeling contributes greatly to the 'green' mark of a product which frequently happens outside or above the individual firm level (Woolverton p.93 2010). There is a disconnect between firms' statements on sustainability and product labeling which, paired with firms that are not truthful about their products from the beginning, lead to skepticism of consumers in the market.

While green consumers should be conscious about the certain downfalls of green labeling and green marketing, there are firms that are truly working towards improved environmental sustainability not only for profit gain but as their social responsibility; these firms make strides to 'green' organizations and firms. In order for a firm to do this, they must "fully integrate green 
initiatives across all aspects of the business" (Cronin p.164 2011). Of course this does not just happen overnight, there are individuals and groups who drive implementation of new regulations and procedures, these people have been termed 'green champions' and play a crucial role on the firm side to advance green marketing and sustainability (Cronin p.164 2011).

\section{Case Study:}

\section{The Case of Amazon.com}

Amazon is the largest company globally with the majority of sales and revenue coming from Amazon.com. With a new era in e-commerce businesses it is important to take a look at their environmental impacts, even those we do not see on a day to day basis. From a simple glance, shopping online seems as though it would be beneficial to everyone, consumers get what they are looking for-at what they believe to be a lower cost-and fewer trips to stores and malls would cut down on transportation costs and emissions for individuals; Unfortunately, it is not this simple (Mathews 2001).

For Amazon's ultra fast shipping and delivery, along with their other features, there are some apparent environmental downfalls. Many consumers when they go out for errands purchase multiple items in one outing, with e-commerce stores it is easy to only purchase one or two items and have them delivered to your front door. The sheer amount of packaging waste contributes to environmental waste with Amazon.com shipping an average of 165 billion packages in the United States alone each year (Bird 2018). Many consumers are becoming aware of this immense amount of waste produced by 
e-commerce businesses and begin to feel guilt and frustration over the issue... and e-commerce businesses like Amazon are listening. There is no simple solution to this problem but an early measure by Amazon to replace boxes with envelopes for smaller items and purchases can cut down on waste (Bird 2018).

These costs to the environment are a common topic for e-commerce businesses but another factor many may not consider is also producing a significant negative impact on the environment: cloud computing and servers. The convenience of e-commerce business is paired with a detrimental amount of energy use for the cloud and servers (Balasooriya 2016). Many consumers fail to consider this aspect of environmental concern because it is completely unseen to them, the electricity and energy used for an individual consumer's computer to run while browsing e-commerce sites is insignificant compared with the cost of operating the trillion dollar company of Amazon constantly. Cloud computing companies are working to make green solutions to decrease energy consumption for their products. With a demand for the lowest prices as well as a demand for sustainability, profit maximization is not the only determinant any longer. Cloud computing companies that source their energy from renewable sources greatly contribute to emissions reduction.

Online retail is only increasing in popularity and with the demand for more sustainable products and services, companies like Amazon are listening and taking action. While e-commerce businesses cannot reasonably implement a zero waste policy today, there are steps for improvement. 
Amazon has voiced its commitment to becoming a more environmentally friendly company with a goal of net zero carbon by the year 2040; this would be done through a number of avenues including electric vehicles for shipping and delivery, using wind and solar power, and packaging items with more sustainable, recyclable material (Amazon.com).

\subsection{How Firms Incentivise Consumers}

Consumers and firms are the two largest components of the green market and interaction between the two is what makes the market successful and continues to expand the market. Using basic marketing strategies, along with knowledge of firms participating in green marketing and the consumers who desire to purchase environmentally sustainable products, allows for growth in the market and connects the two.

There are several ways firms can incentivise green consumers, but this can only be successful if the firm has a deep understanding of the green consumer and why they make their purchasing decisions. Using the simple price, product, promotion, and place (4ps) marketing tools allows firms to use their knowledge of green consumers to their advantage. Modeling green marketing should contain all four P's of marketing: producers should offer ecological products which do not contaminate the environment, price should be determined based on the firm's expectation of the product (higher price for extra effort to make a product sustainable or lower price to encourage consumers to purchase sustainable products over others), environmentally friendly packaging should be used, and promoting the efforts made to create and distribute an environmentally sustainable product (Grundey p.132-133 2008). 


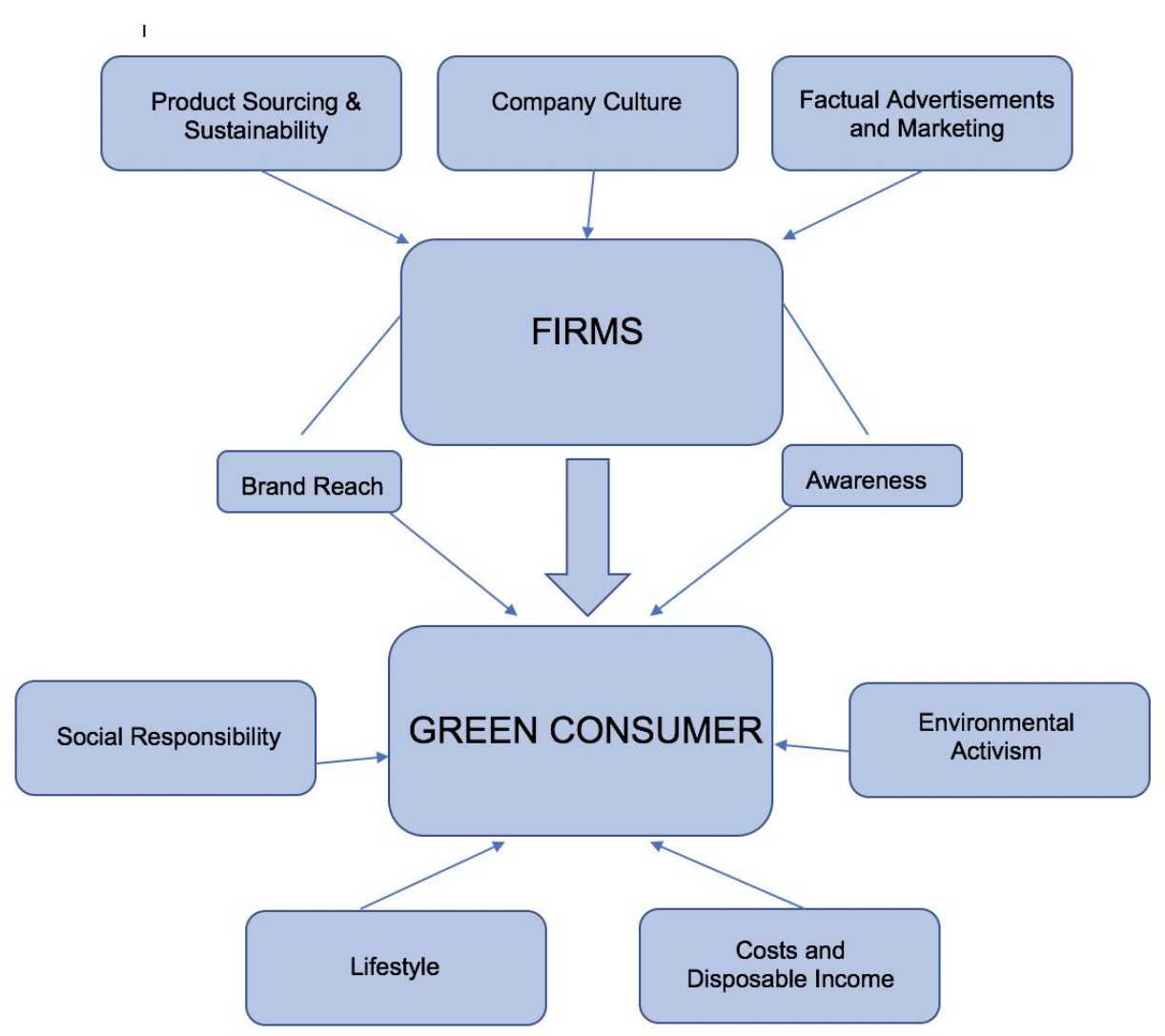

Figure 7: Flow of ideas in green marketing to connect firms to green consumers

Figure 7 above shows essential components of the green market on the firm and consumer side. In order for firms to incentivise consumers it is the role of the firm to understand the ideals and objectives of the green consumer in order to best produce products that are of interest to the segment in order to take advantage of the profit associated with the growing market.

In order for a firm to make a profit from the green consumer they must understand how to reach the green consumer; figure 7 above shows the flow of producer to consumer which is necessary to understand the correlation between green producers and green consumers. By understanding the green consumer side of purchasing better, producers and firms can work to satisfy the demand of green consumers and understand their wants and buying purchases rather 
than simply marking a product as green and facing future scrutiny. We can look at green consumer segment two from the previous section of green consumers most likely to purchase green products but also look into what a firm can do to attract these consumers to increase a company's bottom line while attracting enduring and engaging customers.

We have seen that the active green consumer is most concerned with social responsibility, lifestyle, costs, and environmental activism. Firms should focus on these aspects to bring in green consumers. Once a firm fully understands the motives of the green consumer they are attempting to reach, they should focus first on the lifestyle aspect of the consumer group. While every section holds importance to the group, lifestyle will allow a firm to create a consumer-seller bond. Once this key aspect falls into place, social responsibility, cost, and environmental action will follow which the firm must be ready to accommodate with accurate advertising, authentic practices and customer reach.

\subsection{Conclusion}

In order for firms to take full advantage of green consumers and make higher profit margins their understanding of the consumer segment and their practices must be aligned. To target the best prospective consumers firms should focus their resources on individuals who are persistent and advocate for increased environmental sustainability with a willingness to pay for the specialized goods and services. These consumers tend to be between 25-54 years old with high levels of education, high income, and knowledgeable about global and local environmental issues which are used in their purchasing decisions (Finisterra 2010). Green consumers who actively seek products that align with their environmental beliefs feel obligated to purchase with social responsibility, lifestyle, costs, and environmental activism as key components of the 
decision making process. In an effort to reach these consumers firms should place special emphasis and resources towards their sustainability and product sourcing, their company culture, and creating factual marketing for their products. Active work on awareness and a firm's brand will allow connectivity between firms and green consumers.

\section{References}

Balasooriya, Prasanna NLN, Santoso Wibowo, and Marilyn Wells. "Green cloud computing and economics of the cloud: Moving towards sustainable future." GSTF Journal on Computing (JoC) 5.1 (2016): 15.

Bhardwaj, Vertica, and Ann Fairhurst. "Fast fashion: response to changes in the fashion industry." The international review of retail, distribution and consumer research 20.1 (2010): 165-173.

Bird, Jon. "What A Waste: Online Retail's Big Packaging Problem.” Forbes.com. July 29, 2018. WEB.

Bonini, Sheila, and Jeremy Oppenheim. "Cultivating the green consumer." Stanford Social Innovation Review 6.4 (2008): 56-61.

Brown, Marilyn A., Frank Southworth, and Andrea Sarzynski. Shrinking the carbon footprint of metropolitan America. Washington, DC: Brookings Institution, 2008.

Church, J. M. (1994). market solution to green marketing: Some lessons from the economics of information. Minnesota Law Review, 79(2), 245-324 
Cronin, J. J., Smith, J. S., Gleim, M. R., Ramirez, E., \& Martinez, J. D. (2011). Green marketing strategies: an examination of stakeholders and the opportunities they present. Journal of the Academy of Marketing Science, 39(1), 158-174.

Do Paco, A. M. F., Raposo, M. L. B., \& Leal Filho, W. (2009). Identifying the green consumer: A segmentation study. Journal of Targeting, Measurement and Analysis for Marketing, 17(1), 17-25.

Finisterra do Paço, A. M., \& Raposo, M. L. B. (2010). Green consumer market segmentation: empirical findings from Portugal. International Journal of Consumer Studies, 34(4), 429-436.

Grant, J. (2008). Green marketing. Strategic direction.

Grundey, D., \& Zaharia, R. M. (2008). Sustainable incentives in marketing and strategic greening: the cases of Lithuania and Romania. Technological and Economic

Development of Economy, 14(2), 130-143.

Hertwich, E. G., \& Peters, G. P. (2009). Carbon footprint of nations: A global, trade-linked analysis. Environmental science \& technology, 43(16), 6414-6420.

Jones, Christopher M., and Daniel M. Kammen. "Quantifying carbon footprint reduction opportunities for US households and communities." Environmental science \& technology 45.9 (2011): 4088-4095.

Joy, Annamma, et al. "Fast fashion, sustainability, and the ethical appeal of luxury brands." Fashion theory 16.3 (2012): 273-295.

Koo, Wanmo, and Hyejune Park. "Critical atmospheric cues in designing online stores: The case of Amazon. com." International Journal of Marketing Studies 9.1 (2017): 37-45. 
Lindsey, Rebecca. "Climate Change: Atmospheric Carbon Dioxide.” National Oceanic and Atmospheric Administration. Climate.gov. August 14, 2020. WEB.

Matthews, H. Scott, Chris T. Hendrickson, and Denise Soh. "The net effect: Environmental implications of e-commerce and logistics." Proceedings of the 2001 IEEE International Symposium on Electronics and the Environment. 2001 IEEE ISEE (Cat. No. 01CH37190). IEEE, 2001.

Suki, N. M., Suki, N. M., \& Azman, N. S. (2016). Impacts of corporate social responsibility on the links between green marketing awareness and consumer purchase intentions. Procedia Economics and Finance, 37(2), 262-268.

Woolverton, A., \& Dimitri, C. (2010). Green marketing: Are environmental and social objectives compatible with profit maximization?. Renewable Agriculture and Food Systems, 25(2), 90-98. 